\title{
ИСПОЛЬЗОВАНИЕ ИНФОРМАЦИОННО- КОММУНИКАЦИОННЫХ ТЕХНОЛОГИЙ НА ОСНОВЕ ДИСТАНЦИОННОГО ОБУЧЕНИЯ В ПРОЦЕССЕ ПОДГОТОВКИ БУДУЩИХ УЧИТЕЛЕЙ МУЗЫКИ
}

\author{
Макашева М. С., к.п.н., старший преподаватель Кызылординского университета имени \\ Коркыт Ата, Казахстан \\ Пальмбетова А. Б., преподаватель Кызылординского университета имени Коркыл Ата, \\ Казахстан
}

\section{DOI: https://doi.org/10.31435/rsglobal_conf/25022021/7423}

\begin{abstract}
The article deals with the use of information and communication technologies in the process of instrumental training of music teachers based on distance learning. The analysis of comparing and matching different viewpoints of modern teachers from the USA, Russia and Kazakhstan, who explore the issues regarding the use of information and communication technologies in the process of individual music lessons in the context of distance learning, was carried out. The practical guidelines for the use of information and communication technologies in the process of distance learning were developed to improve the performing skills of the future music teacher. Based on the applied research on the use of distance learning in the process of training specialists and practical work in the field of musical and performing pedagogy, the pedagogical terms for the use of information and communication technologies were determined. The analysis of the application possibilities was carried out and the pedagogical terms for the use of information and communication technologies in the training of future music teachers were suggested in this article.
\end{abstract}

Keywords: information and communication technologies, process of training music teachers, distance learning, musical performance disciplines.

Введение. Эпидемия, происходящая в Казахстане и во всем мире, оказывает свое влияние на систему образования. Подготовка будущих учителей музыки в условиях дистанционного обучения требует новой организации профессионального образовательного процесса. Переход на онлайн-режим музыкально-исполнительских дисциплин, проводимых еще с Добаховского периода в традиционной форме живого общения преподавателя и студента, несомненно, стал одной из проблем, волнующих мировых ученых в области музыкальной педагогики [1].

В современных условиях возникла необходимость создания единого информационнообразовательного пространства, включающего электронные источники информации, виртуальные музыкальные инструменты, базы данных виртуальных библиотек, электронные учебные пособия, видеоуроки, киберпространства. Важность дистанционного обучения для нас заключается в повышении уровня профессиональной инструментальной подготовки обучающихся путем создания единой информационной системы образования $[2,3]$.

Цикл музыкально-инструментальных дисциплин специальности "Музыкальное образование" включает специальные музыкальные дисциплины по инструментальной подготовке (фортепиано, баян, домбра) и требует постоянного развития творческих способностей обучающегося в контексте совершенствования исполнительского мастерства, расширения музыкального репертуара и формирования навыков публичного сценического исполнения. Поэтому мы решили всесторонне рассмотреть применение информационнокоммуникационных технологий в процессе освоения предмета музыкальный инструмент (фортепиано. домбра) в подготовке педагога-музыканта на основе дистанционного обучения.

Цель нашей работы: совершенствование исполнительского мастерства будущего учителя музыки в процессе дистанционного образования на основе применения информационно-коммуникационных технологий.

Методы исследования.

- Теоретические методы: методы анализа и синтеза, сравнения и сопоставления различных точек зрения современных педагогов США, России и Казахстана, исследующие вопросы использования информационно-коммуникационных технологий в процессе индивидуальных музыкальных занятий в контексте дистанционного обучения. 
- Эмпирические методы: косвенное и включенное наблюдение, изучение контентов проведения индивидуального занятия по классу фортепиано, размещенный в режиме открытого доступа в сети интернет; изучение прикладных исследований, где рассматриваются различные аспекты использования информационно-коммуникационных технологий в подготовке будущих музыкальных специалистов; сравнительный анализ полученных результатов, раскрывающих эффективность проведенной практической работы.

Как показал анализ исследуемой проблемы, в прикладных исследованиях рассматриваются различные аспекты использования информационно-коммуникационных технологий в подготовке будущих музыкальных специалистов: сотрудники учебнометодической лаборатории «Музыкальная компьютерная технология» Российского государственного педагогического университета им. А. И. Герцена организуют курсы по данному направлению и проводят научно-исследовательскую работу; на ресурсе Казахстанской республиканской межвузовской электронной библиотеки Западно-Казахстанского университета им. М. Утемисова включены видеолекции по дисциплинам «Музыкальное образование и вокал», «История зарубежной музыки».

Вместе с тем, преподаватель частной школы в Сан-Франциско Н. Тер исследовала вопросы организации рабочего места учителя и использование элементов ИКТ при дистанционном проведении урока фортепиано, в том числе виртуального инструмента; педагог России Вячеслав Слаква ведет работу по разработке методических указаний по освоению инструмента фортепиано на основе использования сетей скайп, Zoom, What's Up.

Кроме того, наше исследование показало, что контенты для проведения индивидуального занятия по классу фортепиано, размещенный в режиме открытого доступа в сети интернет, представляют собой чат-занятия, проводимые с помощью гаджета, или технические приемы исполнения музыкального произведения, ограничивающиеся инструментальным исполнением преподавателя.

В целях совершенствования исполнительского мастерства будущего учителя музыки в процессе дистанционного образования на основе применения информационнокоммуникационных технологий были разработаны следующие практические указания:

1. Перед обучающимся обязательно должна располагаться партитура музыкального произведения.

2. В целях одновременного использования музыкального текста с фортепианным исполнением обучающийся должен располагаться перед инструментом и девайс должен отображать полный объем клавиатуры.

3. Для необходимости приобретения навыков исполнительского мастерства фрагменты произведений, выполненных на инструменте преподавателем, должны быть повторены обучающимся.

4. Обучающийся в рамках изучаемого произведения обязательно должен работать со всеми видами гамм, аккордов, арпеджио.

Опираясь на наше исследования мы определили педагогические условия применения информационно-коммуникационных технологий. исполнительская работа над музыкальным произведением, в контексте нашего исследования, условно состоит из трех этапов, тесно связанных между собой:

I этап - полное ознакомление с нотным текстом произведения в контексте нашего исследования (определение музыкального языка, стиля композитора, определение границ, размеров, этапов, ритма разделов, установление подходящего варианта аппликатуры);

II этап - работа с динамическими знаками и приобретение технических навыков (работа с фразами произведения);

III этап - раскрытие художественного образа произведения (сценическое исполнение).

С целью определения видов проводимых практических работ мы использовали для каждого этапа различные музыкальные произведения разных композиторов.

Информационно-коммуникационные технологий, которые применялись на I этапе исполнительской работы: технология развивающего обучения, кейс-технология, электронная информационная база, таксономия Блума, индивидуальная работа с обучающимся, дифференцированное обучение, программа Final.

В качестве текста темы мы использовали партитуру произведения Д. Кабалевского "Вальс".

Анализ музыкального произведения: пьеса состоит из 3 простых частей и заключения (coda). Размер-3/4, тональность - d-moll, в среднем темпе (умеренно). Произведение начинается 
с третьей слабой доли неполного такта. Музыкальный материал I предложения связывается с четырехтактной лигой через динамический знак piano. Мелодия первого предложения и второго предложения требует кантилены. Упомянутые фразы связаны со штрихом legato. Bo втором предложении материал первого предложения повторяется. В общем, произведение начинается с динамического знака ріаno. Этот динамический знак используется в первом периоде и продолжается до конца второго периода.

В работе над нотным текстом, в качестве обратной связи обучающий представляет самостоятельную ознакомительную практическую работу онлайн. По результатам данной работы студент оценивает себя и на основе анализа работы преподавателем общая оценка выставляется в систему Platonus.

По итогам самостоятельной работы обучающегося преподавателем определяется следующее задание: сыграть произведение двумя руками на клавиатуре виртуального пианино, загрузить на платформу Classroom.

Информационные технологии, используемые на II этапе работы над музыкальным произведением: Mail.ru платформа, программа Bandicam, платформа Classroom, информационные ресурсы, скайп, What's Up сети, виртуальное пианино.

Работа над динамическими оттенками музыкального произведения, a также практическое исполнение приобретенных технических навыков пьесы. В качестве нотного текста мы использовали партитуру произведения Ю. Литовко "Пьеса" (работа с динамическими знаками и приобретение технических навыков): I часть - простой период из 8 тактов. Музыкальный материал данного периода состоит из двух тактовых секвенций, Соединенных штрихом legato. В общем, произведение начинается с динамического знака ріапо. Этот динамический знак используется в первом периоде. Раздел II представляет собой простой период из 8 тактов. Музыкальный материал данного периода также записан в виде секвенции. В этом разделе вы найдете динамический знак mezzo piano. В конце предложения встречаются две вольты из-за знака репризы. Следовательно, необходимо повторить предложение дважды. Поэтому в тексте III части повторяется музыкальный материал II части. В конце музыкального произведения применяется знак ritenuto и пьеса заканчивается динамическим знаком ріапо.

Проведен динамический, технический анализ музыкального произведения. Работа со штрихом legato, мелодией в партии правой руки, динамическими знаками piano, mezzo piano будет продолжена с использованием программы Bandicam.

На III этапе работы над музыкальным произведением применялись следующие технологии: технология дифференцированного уровневого обучения, платформа Zoom, таксономия Блума, технология кейса, электронная информационная база, виртуальное пианино.

На данном этапе нашей работы «раскрытие художественного образа музыкального произведения (сценическое исполнение)» в качестве нотного текста мы выбрали Этюд №46 (тему Паганини) И. Я. Берковича. В процессе исполнения произведения продолжается работа над фразами, динамическими знаками на платформе Zoom. Но основной целью этого этапа является полноценное описание произведения обучающимся и уровень владения инструментом в концертном исполнении.

Результаты исследования. Опираясь на прикладные исследования применения дистанционного обучения в процессе подготовки специалистов и практическую работу в направлении музыкально-исполнительской педагогики, мы определили педагогические условия применения информационно-коммуникационных технологий:

1. Выявить и использовать в практической работе образовательные платформы, необходимые информационно-коммуникационных технологии, подходящие для проведения индивидуальных инструментальных занятий;

2. Разделить процесс освоения музыкального произведения на этапы, где определение содержания работ зависит от тематики развития музыкально-исполнительских способностей обучающегося;

3. Провести работу в онлайн режиме, направленной на тесное творческокоммуникационное общение с обучающимся, основу которого составляет полное ознакомление с текстом музыкального произведения, работа с динамическими знаками и приобретением технических навыков, а также возможность раскрытия художественного образа инструментального произведения;

4. Изучить рациональные аспекты новых информационных технологий, современных электронных программ, электронных библиотек, образовательных платформ, внедряемых в 
процесс дистанционного образования в системе профессиональной подготовки будущего учителя музыки, что будет способствовать использованию обучающимися в практической работе в условиях школьных занятий.

Заключение. В своей работе мы провели анализ возможностей применения и предложили педагогические условия использования информационно-коммуникационных технологий в подготовке будущих учителей музыки. Применение педагогической парадигмы, определяющей систему освоения музыкального произведения в пространстве информационных технологий, является перспективным направлением поиска ресурсов современного музыкального исполнительства. Использование информационно-коммуникационных технологий в подготовке педагога-музыканта позволяет активизировать познавательную деятельность обучающегося, вести ее по пути целостного развития духовного и творческого потенциала.

\section{ЛИТЕРАТУРА}

1. Никуличева Н. Дистанционное обучение в образовании: организация и реализация / Н. Никуличева. - M.: LAP Lambert Academic Publishing, 2019. - 220 c.

2. Бекенова Д. У. Информационные технологии в музыкальном образовании [Текст]/Д.У. Бекенова, Ж.А. Мухатаева// Актуальные задачи педагогики: материалы III междунар. науч. конф. (г. Чита, февраль 2013 г.). - Чита: Молодой ученый, 2013. http://www.moluch.ru/conf/ped/archive/67/3328/

3. Евдокимова Т. С. Развитие творческих способностей учащихся в процессе обучения игре на фортепиано с использованием передовых педагогических технологий. - режим доступа: http://nsportal.ru/npospo/kultura-i-iskusstvo/library/razvitie-tvorcheskihsposobnostey-uchashchihsya-v-processe 